\title{
Evaluation of knowledge among general dentists in treatment of traumatic injuries in primary teeth: A cross-sectional questionnaire study
}

\author{
Dhanalakshmi Ravikumar ${ }^{1}$, Ganesh Jeevanandan ${ }^{1}$, E. M. G. Subramanian ${ }^{1}$
}

Correspondence: Dr. Dhanalakshmi Ravikumar

Email: dhana9677@gmail.com
'Department of Pedodontics and Preventive Dentistry, Saveetha Dental College and Hospitals, Chennai, Tamil Nadu, India

\section{ABSTRACT}

Objective: The purpose of the present study was to assess the knowledge of General dentist regarding the management of dental traumatic injuries of primary teeth. Materials and Methods: A total of 100 general dentists were selected and a validated questionnaire was distributed among the dentist to assess their knowledge on treatment strategies regarding traumatized primary teeth. Statistical Analysis: Data were entered into SPSS version 20.0 for percentages. The correct answers were tested in relation to the dentists' years of experience using the Chi-square test. Results: Analyzing the questionnaire for knowledge, $49 \%$ of dentists answered accurately regarding avulsed primary teeth, 36\% of dentists answered appropriately regarding crown and root fractures, and 55\% of dentists gave appropriate answers regarding luxation injuries. Chi-square test showed a statistically significant difference only for 2 questions in relation to the dentist's years of experience $(P<0.05)$. Conclusion: There is a lack of consistency in the knowledge among general dentist regarding traumatic dental injuries of primary teeth. There is a need to create awareness and education regarding traumatic injuries of primary teeth.

Key words: General dentist, knowledge, traumatic injuries

\section{INTRODUCTION}

Trauma in primary dentition is a common occurrence between 2 and 4 years of age ${ }^{[1]}$ and the incidence ranges from $4 \%$ to $30 \% .{ }^{[2]}$ Dental injuries can vary from simple concussion to a severe damage involving the surrounding structures of the tooth. ${ }^{[3]}$ These traumatic injuries to the primary dentition present with a special challenge to the dentist, as it creates panic among the parents and the dentist and creates anxiety and fear in the young child.

The major hindrance in delivering appropriate dental care by the dentist during this situation and the dentist fear of any additional risk to a permanent

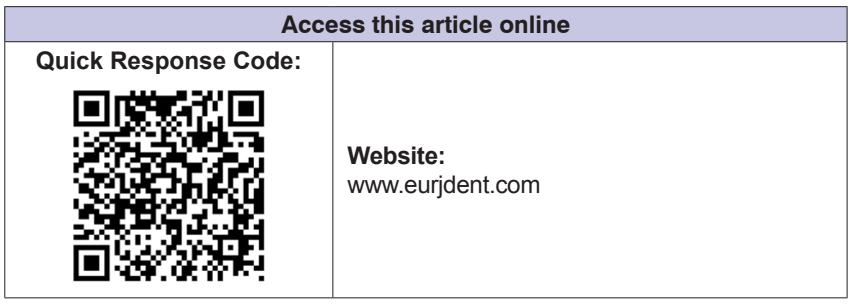

successor. ${ }^{[4]}$ Primary teeth play an imperative role in the self-esteem of the preschool children and also plays a pivotal role in speech development, esthetics, and function. ${ }^{[5,6]}$ The maintenance of the primary dentition is important to guide the eruption of permanent teeth and traumatic dental injuries may affect this balance, and hence, it is considered as an important oral health problem. ${ }^{[7]}$ In addition, research carried out by Da Silva Assunção et al. had stated that trauma to primary teeth leads to alterations in the succedaneous dentition. ${ }^{[8]}$ However, only a

This is an open access article distributed under the terms of the Creative Commons Attribution-NonCommercial-ShareAlike 3.0 License, which allows others to remix, tweak, and build upon the work non-commercially, as long as the author is credited and the new creations are licensed under the identical terms.

For reprints contact: reprints@medknow.com

How to cite this article: Ravikumar D, Jeevanandan G, Subramanian EM. Evaluation of knowledge among general dentists in treatment of traumatic injuries in primary teeth: A cross-sectional questionnaire study. Eur $\mathrm{J}$ Dent 2017;11:232-7.

DOI: 10.4103/ejd.ejd_357_16 
few sporadic case reports have been published on the management of traumatic injuries in primary teeth, and only a few suggests the positive treatment outcome in primary dentition. ${ }^{[9,10]}$

Several studies have assessed the knowledge of emergency management of traumatic injuries in permanent teeth, but not in primary teeth. ${ }^{[11,12]}$ Most of these studies concluded the need for better communication between the dentistand the community to create awareness. Treatment of traumatic dental injuries in primary teeth is often more complex, and a precise diagnosis and meticulous follow-up examinations are always required. Hence, there may be a need for a specialized staff for a periodic follow-up depending on the degree of severity. ${ }^{[13]}$ However, there is no consensus in the literature concerning the treatment options for treating traumatized primary teeth, and this may contribute to new studies focused on trauma in the primary dentition There is a lack of well-supported studies to guide dentist in selecting appropriate treatment options for traumatized primary teeth.

Therefore, this study was aimed to assess the level of knowledge of general dentist in treating traumatized primary teeth and creating awareness.

\section{MATERIALS AND METHODS}

\section{Ethical approval}

The present cross-sectional study was carried out after obtaining Ethical approval from the Institutional review board (SRB/STPGe) of Saveetha Dental College.

\section{Study design}

The survey was conducted in a single dental school in Chennai. This was one of the first studies to assess the knowledge of dentist in treating traumatic dental injuries in primary teeth, a nonprobability purposive sampling frame was designed. Since it was easy to recruit the study population from a single dental school, purposive sampling technique was chosen. A sample of 100 General Dentists working in a Single Dental School, Chennai, India was included in the study.

The study was undertaken in two stages stage 1 and Stage 2. Stage 1 comprised formulating, designing, and validating the questionnaire, whereas Stage 2 tested the validated questionnaire among 100 general dentists.
Stage 1 (designing and validation of questionnaire) A standardized self-constructed questionnaire was formulated using American Academy of Pediatric Dentistry (AAPD) guidelines by two investigators (DR, GJ). ${ }^{[1]}$ Both the investigators (DR, GJ) independently formulated the questionnaire, and after a consensus, they arrived at a final list of 15 questions. The questionnaire was based on the clinical scenario, which includes questions regarding the treatment strategies for primary tooth crown fracture, crown-root fractures, root fractures, and avulsion to assess the clinical knowledge of General dentist along with their years of clinical experience.

Initially, content validation of the questionnaire was performed by circulating the questionnaire to 10 qualified Paediatric dentists. A panel discussion was conducted among 10 qualified Pediatric dentists, and they had rated the questionnaire using content validity ratio. ${ }^{[14-16]}$ There was a good agreement between the investigators, with a rating of $>0.7$. Finally, the questionnaire was distributed to 10 random General dentists for face validation, and it was evaluated using 5-point Likert scale.

\section{Stage 2 (testing of validated questionnaire)}

After the content and face validation, the questionnaire was distributed to 100 General dentists to complete the questionnaire. Distribution and collection of the questionnaire were done by one of the Pediatric dentists (DR).

\section{Statistical analysis}

Data were collected and entered into SPSS software version (SPSS Inc., Chicago, IL, USA) 20.0 for percentages. The correct answers were tested in relation to the dentists' years of experience using the Chi-square test.

\section{RESULTS}

A total of 100 questionnaire were distributed. All the questionnaire were filled with $100 \%$ response rate. Among the 100 respondents, 50 were male dentists and 50 were female dentists between the age group of 25 and 45 years.

Table 1 depicts the percentage of different answers given by the dentist. Analyzing the questions separately, question 10 (A 2.5-year-old child reports with an extrusion of an upper central incisor with $<3 \mathrm{~mm}$, what will be the ideal treatment) presented 
Ravikumar, et al.: Dentists' knowledge in traumatic injuries of primary teeth

\begin{tabular}{|c|c|c|c|c|c|}
\hline \multirow{2}{*}{$\begin{array}{l}\begin{array}{l}\text { Question } \\
\text { number }\end{array} \\
\text { Q1 }\end{array}$} & \multirow{2}{*}{$\begin{array}{l}\text { Questionnaire } \\
\text { Can an avulsed primary } \\
\text { tooth be replanted }\end{array}$} & \multicolumn{4}{|c|}{ Percentage of different answers given by the dentist (\%) } \\
\hline & & (a) Yes $(65 \%)$ & (b) No $(24 \%)$ & (c) Not sure $(11 \%)$ & \\
\hline Q2 & $\begin{array}{l}\text { Is there a recommended } \\
\text { age for replantation of } \\
\text { avulsed primary tooth }\end{array}$ & (a) $2-4$ years $(34 \%)$ & (b) $>4$ years $(11 \%)$ & $\begin{array}{l}\text { (c) No age } \\
\text { difference }(32 \%)\end{array}$ & $\begin{array}{l}\text { (d) Cannot be } \\
\text { reimplanted (23\%) }\end{array}$ \\
\hline Q3 & $\begin{array}{l}\text { Common reason for } \\
\text { avulsion of primary tooth }\end{array}$ & (a) Short roots $(18 \%)$ & $\begin{array}{l}\text { (b) Resilient alveolar } \\
\text { bone and short } \\
\text { roots }(32 \%)\end{array}$ & $\begin{array}{l}\text { (c) Short } \\
\text { crown }(1 \%)\end{array}$ & $\begin{array}{l}\text { (d) All the } \\
\text { above }(49 \%)\end{array}$ \\
\hline Q4 & $\begin{array}{l}\text { Is there any difference in } \\
\text { the management of avulsed } \\
\text { primary and permanent teeth }\end{array}$ & (a) Yes $(60 \%)$ & (b) No (15\%) & (c) Not sure $(25 \%)$ & \\
\hline Q5 & $\begin{array}{l}\text { A } 2.5 \text {-year-old child reports with } \\
\text { a crown fracture involving pulp, } \\
\text { what will be the ideal treatment? }\end{array}$ & $\begin{array}{l}\text { (a) Pulpectomy and } \\
\text { calcium hydroxide } \\
\text { dressing }(65 \%)\end{array}$ & (b) Pulpectomy (28\%) & (c) Extraction (2\%) & $\begin{array}{l}\text { (d) Not sure of } \\
\text { treatment }(5 \%)\end{array}$ \\
\hline Q6 & $\begin{array}{l}\text { A } 2.5 \text {-year-old child reports with } \\
\text { a crown fracture extending to } \\
\text { only cervical region of the root, } \\
\text { what will be the ideal treatment }\end{array}$ & (a) Pulpectomy (37\%) & $\begin{array}{l}\text { (b) Removal of } \\
\text { fragment followed by } \\
\text { pulpotomy }(34 \%)\end{array}$ & (c) Extraction (16\%) & $\begin{array}{l}\text { (d) Not sure of } \\
\text { treatment }(13 \%)\end{array}$ \\
\hline Q7 & $\begin{array}{l}\text { A 4-year-old child reports with } \\
\text { root fracture with no coronal } \\
\text { fragment displaced, what will } \\
\text { be the treatment option }\end{array}$ & $\begin{array}{l}\text { (a) No treatment } \\
\text { required, wait and } \\
\text { watch }(42 \%)\end{array}$ & $\begin{array}{l}\text { (b) Extract } \\
\text { the coronal } \\
\text { fragment }(14 \%)\end{array}$ & $\begin{array}{l}\text { (c) Extraction of } \\
\text { coronal and apical } \\
\text { fragment }(22 \%)\end{array}$ & $\begin{array}{l}\text { (d) No treatment } \\
\text { required }(22 \%)\end{array}$ \\
\hline Q8 & $\begin{array}{l}\text { A 4-year-old child reports } \\
\text { with root fracture with coronal } \\
\text { fragment displaced, what } \\
\text { will be the ideal treatment }\end{array}$ & $\begin{array}{l}\text { (a) Repositioning and } \\
\text { splinting the coronal } \\
\text { fragment }(32 \%)\end{array}$ & $\begin{array}{l}\text { (b) Extract } \\
\text { the coronal } \\
\text { fragment }(17 \%)\end{array}$ & $\begin{array}{l}\text { (c) Extraction of } \\
\text { coronal and apical } \\
\text { fragment }(31 \%)\end{array}$ & $\begin{array}{l}\text { (d) Not } \\
\text { sure }(20 \%)\end{array}$ \\
\hline Q9 & $\begin{array}{l}\text { A } 4.5 \text {-year-old child report with } \\
\text { mobile upper central incisor with } \\
\text { bleeding from gingival crevice, } \\
\text { what will be the ideal treatment }\end{array}$ & $\begin{array}{l}\text { (a) No treatment } \\
\text { required, wait and } \\
\text { watch }(53 \%)\end{array}$ & (b) Pulpectomy (10\%) & (c) Extraction (14\%) & $\begin{array}{l}\text { (d) Not } \\
\text { sure }(22 \%)\end{array}$ \\
\hline Q10 & $\begin{array}{l}\text { A } 2.5 \text {-year-old child reports with } \\
\text { a extrusion of upper central } \\
\text { incisor with }<3 \mathrm{~mm} \text {, what } \\
\text { will be the ideal treatment }\end{array}$ & (a) Pulpectomy (12\%) & $\begin{array}{l}\text { (b) Careful } \\
\text { repositioning and wait } \\
\text { and watch }(72 \%)\end{array}$ & (c) Extraction (4\%) & $\begin{array}{l}\text { (d) Not sure of } \\
\text { treatment }(12 \%)\end{array}$ \\
\hline Q11 & $\begin{array}{l}\text { A 5.5-year-old child reports with } \\
\text { a extrusion of upper central } \\
\text { incisors with more than } 3 \mathrm{~mm} \text {, } \\
\text { what will be the ideal treatment }\end{array}$ & $\begin{array}{l}\text { (a) Careful } \\
\text { repositioning (36\%) }\end{array}$ & (b) Pulpectomy (10\%) & (c) Extraction (36\%) & $\begin{array}{l}\text { (d) Not sure of } \\
\text { treatment }(18 \%)\end{array}$ \\
\hline Q12 & $\begin{array}{l}\text { A 3-year-old child reports with } \\
\text { a palatal luxation of tooth with } \\
\text { no occlusal interference, what } \\
\text { will be the ideal treatment }\end{array}$ & $\begin{array}{l}\text { (a) Allow for spontaneous } \\
\text { reposition of tooth }(65 \%)\end{array}$ & $\begin{array}{l}\text { (b) Perform } \\
\text { pulpectomy (14\%) }\end{array}$ & (c) Extraction (4\%) & $\begin{array}{l}\text { (d) Not } \\
\text { sure }(17 \%)\end{array}$ \\
\hline Q13 & $\begin{array}{l}\text { A 3-year-old child reports with } \\
\text { a palatal luxation of tooth with } \\
\text { severe occlusal interference, } \\
\text { what will be ideal treatment }\end{array}$ & $\begin{array}{l}\text { (a) Gently reposition } \\
\text { with combined labial } \\
\text { and palatal pressure } \\
\text { and splinting }(63 \%)\end{array}$ & (b) Pulpectomy (9\%) & (c) Extraction (12\%) & $\begin{array}{l}\text { (d) Not } \\
\text { sure }(16 \%)\end{array}$ \\
\hline Q14 & $\begin{array}{l}\text { A 3-year-old child reports with } \\
\text { intrusion of central incisor and } \\
\text { the apex of the root not displaced } \\
\text { with developing tooth germ, } \\
\text { what will be ideal treatment }\end{array}$ & $\begin{array}{l}\text { (a) Tooth left for } \\
\text { spontaneous } \\
\text { repositioning (53\%) }\end{array}$ & $\begin{array}{l}\text { (b) Surgical } \\
\text { replacement and } \\
\text { pulpectomy }(20 \%)\end{array}$ & (c) Extraction (7\%) & $\begin{array}{l}\text { (d) Not sure of } \\
\text { treatment }(20 \%)\end{array}$ \\
\hline Q15 & $\begin{array}{l}\text { A 3-year-old child reports with } \\
\text { intrusion of central incisor and } \\
\text { the apex of the root displaced } \\
\text { with developing tooth germ, what } \\
\text { will be the ideal treatment? }\end{array}$ & $\begin{array}{l}\text { (a) Tooth left insitu } \\
\text { for spontaneous } \\
\text { repositioning }(20 \%)\end{array}$ & $\begin{array}{l}\text { (b) } \\
\text { Pulpectomy (15\%) }\end{array}$ & $\begin{array}{l}\text { (c) } \\
\text { Extraction }(43 \%)\end{array}$ & $\begin{array}{l}\text { (d) Not sure of } \\
\text { treatment }(22 \%)\end{array}$ \\
\hline
\end{tabular}

the largest number of correct answers. On the other hand, question 1 (Can an avulsed primary tooth be replanted) yielded the largest number of incorrect answers [Table 1].
The questionnaire was divided into 3 scenarios, such as questions regarding avulsion of primary tooth, questions regarding crown and root fractures and questions based on luxation injuries. 
Analyzing the questionnaire for knowledge regarding avulsed primary teeth (Question 1-4), 49\% of dentists answered accurately and $51 \%$ of dentists answered irrelevantly. Analysis of the questionnaire regarding crown and root fractures, only $36 \%$ of dentists answered appropriately regarding crown and root fractures. Knowledge regarding luxation injuries (palatal, labial, intrusion, and extrusion), 55\% of dentists gave appropriate answers. Figure 1 depicts the percentage of correct and incorrect answers given by the dentist under each domain.

Table 2 shows the years of experience and the correct answers provided by the dentist. Chi-square test showed a statistically significant difference only for 2 questions in relation to the dentist's years of experience $(P<0.05)$. There was no statistically significant difference evident for other questions and the dentist's years of experience $(P>0.05)$.

\section{DISCUSSION}

This study set out to investigate the knowledge of general dentist in treating traumatized primary teeth. The present study was initiated as one of the preliminary studies to investigate the dentist knowledge using a self-applied questionnaire. The questionnaire used in this research had been validated by content and face validation at the beginning of the study, based on the validation technique explained previously. The aim of this validation process was to gain the experts opinion and to modify the questionnaire in ease of understanding.

The greatest incidence of trauma to the primary teeth occurs between 2 and 3 years of age ${ }^{[4]}$ and the

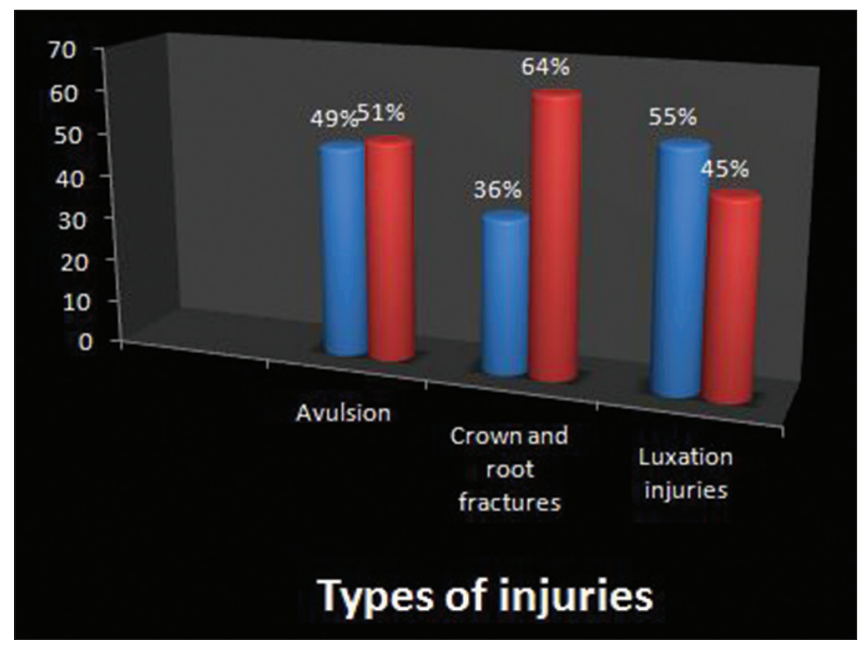

Figure 1: Percentage of correct and incorrect answers for each domain treatment strategy should be dictated by the concern for the safety of the permanent dentition. ${ }^{[1,4]}$ The result of the present study suggests that there was a lack of adequate knowledge about traumatized primary teeth among general dentist.

Avulsion is more common in primary teeth due to the resilient alveolar bone, and the prevalence has been reported to be $5.8 \% \cdot{ }^{[17]} \mathrm{A}$ few case reports have suggested the success and failure of replacement of avulsed tooth. ${ }^{[9,18]}$ Forty-nine percentage of dentist answered accurately to the questions regarding the avulsion of primary teeth. A systematic review performed by Martins-Júnior et al. had stated that there are a lacunae and a lack of high-quality studies to guide clinicians regarding the best approach to treating primary tooth avulsion. ${ }^{[19]}$ Replantation of an avulsed primary tooth is not yet accepted as a treatment option in the guidelines formulated by either AAPD or International Association of Dental Traumatology. ${ }^{[11,20]}$

The incidence of crown fractures in primary dentition accounts about 1\%-3\%. ${ }^{[17,21]}$ Bhayya and Shyagali assessed the prevalence of traumatic injuries of primary dentition in Gulbarga city, India and reported that, crown fracture was the most prevalent type of fractures and the primary reason was due to fall. ${ }^{[12]}$ Sixty-five percentage of dentist answered accurately for crown fracture with pulpal exposure. Although cvek's pulpotomy is one of the treatment modalities for partial pulp exposure, its application is rarely encountered in primary dentition. ${ }^{[13]}$ Kupietzky and Holan suggested a conservative partial pulpotomy as a successful treatment protocol for primary teeth with crown fracture and pulp exposure. ${ }^{[22]}$ According to AAPD guidelines, pulpotomy and calcium hydroxide dressing are the ideal treatment options. ${ }^{[1]}$

Teeth with crown-root fractures and root fractures always present with a higher frequency of premature loss due to poor prognosis and left untreated due to anticipated risk for permanent teeth. Costa et al. looked into the clinical and radiographic sequelae of traumatized primary teeth and concluded that the crown-root fracture was the common type of fracture and presented with higher clinical sequelae. ${ }^{[10]}$ Only $36 \%$ of dentists answered correctly, indicating that, the knowledge regarding the crown and root fractures remains unsatisfactory.

AAPD had dictated treatment protocol for crown-root fracture and root fractures depending on the extent of the fracture. ${ }^{[11]}$ 
Ravikumar, et al.: Dentists' knowledge in traumatic injuries of primary teeth

\begin{tabular}{|c|c|c|c|}
\hline $\begin{array}{l}\text { Question } \\
\text { number }\end{array}$ & Questions & $\begin{array}{c}\text { Pearson's Chi-square value based on } \\
\text { years of experience }(<5 \text { years, } 5-10 \text { years, } \\
>10 \text { years) and the correct answers provided }\end{array}$ & $P$ \\
\hline Q1 & Can an avulsed primary tooth be replanted & 14.786 & $0.02^{*}$ \\
\hline Q2 & $\begin{array}{l}\text { Is there a recommended age for replantation } \\
\text { of avulsed primary tooth }\end{array}$ & 7.182 & 0.30 \\
\hline Q3 & Common reason for avulsion of primary tooth & 11.598 & 0.07 \\
\hline Q4 & $\begin{array}{l}\text { Is there any difference in the management of } \\
\text { avulsed primary and permanent teeth }\end{array}$ & 7.735 & 0.25 \\
\hline Q5 & $\begin{array}{l}\text { A } 2.5 \text {-year-old child reports with a crown fracture } \\
\text { involving pulp, what will be the ideal treatment? }\end{array}$ & 8.440 & 0.20 \\
\hline Q6 & $\begin{array}{l}\text { A } 2.5 \text {-year-old child reports with a crown } \\
\text { fracture extending to only cervical region of } \\
\text { the root, what will be the ideal treatment }\end{array}$ & 9.819 & 0.13 \\
\hline Q7 & $\begin{array}{l}\text { A 4-year-old child reports with root fracture with no coronal } \\
\text { fragment displaced, what will be the treatment option }\end{array}$ & 0.965 & 0.98 \\
\hline Q8 & $\begin{array}{l}\text { A 4-year-old child reports with root fracture with coronal } \\
\text { fragment displaced, what will be the ideal treatment }\end{array}$ & 9.153 & 0.16 \\
\hline Q9 & $\begin{array}{l}\text { A 4.5-year-old child report with mobile upper } \\
\text { central incisor with bleeding from gingival } \\
\text { crevice, what will be the ideal treatment }\end{array}$ & 4.562 & 0.21 \\
\hline Q10 & $\begin{array}{l}\text { A } 2.5 \text {-year-old child reports with a extrusion of upper } \\
\text { central incisor with }<3 \mathrm{~mm} \text {, what will be the ideal treatment }\end{array}$ & 15.962 & $0.04^{*}$ \\
\hline Q11 & $\begin{array}{l}\text { A 5.5-year-old child reports with a extrusion of upper central } \\
\text { incisors with }>3 \mathrm{~mm} \text {, what will be the ideal treatment }\end{array}$ & 6.028 & 0.42 \\
\hline Q12 & $\begin{array}{l}\text { A 3-year-old child reports with a palatal luxation of tooth with } \\
\text { no occlusal interference, what will be the ideal treatment }\end{array}$ & 10.966 & 0.08 \\
\hline Q13 & $\begin{array}{l}\text { A 3-year-old child reports with a palatal luxation of tooth with } \\
\text { severe occlusal interference, what will be ideal treatment }\end{array}$ & 4.978 & 0.54 \\
\hline Q14 & $\begin{array}{l}\text { A 3-year-old child reports with intrusion of central } \\
\text { incisor and the apex of the root not displaced with } \\
\text { developing tooth germ, what will be ideal treatment }\end{array}$ & 1.471 & 0.96 \\
\hline Q15 & $\begin{array}{l}\text { A 3-year-old child reports with intrusion of central incisor } \\
\text { and the apex of the root displaced with developing tooth } \\
\text { germ, what will be the ideal treatment? }\end{array}$ & 8.038 & 0.23 \\
\hline
\end{tabular}

Studies had suggested that luxation injury was the most common type in primary dentition ${ }^{[18,23]}$ and Costa et al. had reported that subluxation was one of the common types of luxation injuries from his series of case reports. ${ }^{[10]}$ AAPD suggested different treatment options depending on the degree of displacement. ${ }^{[11]}$ Assunção et al. suggested Monitoring only' as the most common treatment protocol. ${ }^{[23]}$

Years of dentist experience and the correct answers provided by them was found statistically significant only to 2 question [Table 2]. The statistically significant answers provided were the questions regarding avulsion and extrusion of primary teeth $(P<0.05)$. The reasons for this statistically significant answers may be due to the dentist's years of experience and luxation injuries (33\%) and avulsed tooth $(5.8 \%)$ were the most common type of traumatic injuries encountered as stated previously. ${ }^{[17,18,23]}$ As there was no statistically significant difference encountered between the years of experience and the correct answers for most of the questions, the present study suggests that years of experience has no influential role in the treatment modalities and more awareness and knowledge is required for general dentist in treating traumatized primary teeth.

It is important to emphasize that the present was a cross-sectional study, which evaluated the knowledge in only one dental school. Hence, further longitudinal investigations involving other dental schools as a multi-centric approach are recommended to provide more information for discussion on knowledge on the management of traumatic injuries in primary teeth.

Based on the results of the present study and with the available evidence in the literature, it is clearly evident, that, knowledge and the information regarding the predicted risk, treatment options, and complications are not available for primary dentition. 


\section{CONCLUSION}

With the light of available evidence, this study concludes that there is a need to create awareness and education regarding treatment protocols and the risk of developing complications. This may help the clinician to determine an appropriate treatment protocol and prognosis of traumatized primary teeth.

\section{Financial support and sponsorship}

Nil.

\section{Conflicts of interest}

There are no conflicts of interest.

\section{REFERENCES}

1. Andreason JO, Andreason FM. Textbook and Color Atlas of Traumatic Injuries to the Teeth. $3^{\text {rd }}$ ed. Copenhagen: Munksgaard; 1994. p. 383-420

2. Fried I, Erickson P. Anterior tooth trauma in the primary dentition: Incidence, classification, treatment methods, and sequelae: A review of the literature. ASDC J Dent Child 1995;62:256-61.

3. Al-Obaida M. Knowledge and management of traumatic dental injuries in a group of Saudi primary schools teachers. Dent Traumatol 2010;26:338-41.

4. Flores MT, Malmgren B, Andersson L, Andreasen JO, Bakland LK, Barnett $\mathrm{F}$, et al. Guidelines for the management of traumatic dental injuries. III. Primary teeth. Dent Traumatol 2007;23:196-202.

5. Koroluk LD, Riekman GA. Parental perceptions of the effects of maxillary incisor extractions in children with nursing caries. ASDC J Dent Child 1991;58:233-6.

6. Fymbo L. The relation of malocclusion of the teeth to defects of speech. Arch Speech 1936;1:204-16.

7. Jesus MA, Antunes LA, Risso Pde A, Freire MV, Maia LC. Epidemiologic survey of traumatic dental injuries in children seen at the Federal University of Rio de Janeiro, Brazil. Braz Oral Res 2010;24:89-94
8. Da Silva Assunção LR, Ferelle A, Iwakura ML, Cunha RF. Effects on permanent teeth after luxation injuries to the primary predecessors: A study in children assisted at an emergency service. Dent Traumatol 2009;25:165-70

9. Al-Khayatt AS, Davidson LE. Complications following replantation of a primary incisor: A cautionary tale. Br Dent J 2005;198:687-8.

10. Costa VP, Oliveira LJ, Rosa DP, Cademartori MG, Torriani DD. Crown-root fractures in primary teeth: A case series study of 28 cases. Braz Dent J 2016;27:234-8.

11. American Academy of Pediatric Dentistry. Guidelines for the management of traumatic dental injuries: 3 . Injuries in the primary dentition. Ref Man 2013;37:341-9.

12. Bhayya DP, Shyagali TR. Traumatic injuries in the primary teeth of 4- to 6-year-old school children in Gulbarga city, India. A prevalence study. Oral Health Dent Manag 2013;12:17-23.

13. Oikarinen K, Kassila O. Causes and types of traumatic tooth injuries treated in a public dental health clinic. Endod Dent Traumatol 1987;3:172-7.

14. Sireci SG. The construct of content validity. Soc Indic Res 1998;45:83-117.

15. Rungtusanatham M. Let's not overlook content validity. Decis Line 1998;29:10-3.

16. Fitzpatrick AR. The meaning of content validity. Appl Psychol Meas 1983;7:3-13.

17. Kenwood M, Seow WK. Sequelae of trauma to the primary dentition. J Pedod 1989;13:230-8.

18. Kapur A, Goyal A, Gauba K. Replantation of an avulsed primary incisor: Report of a case with favorable outcome. J Postgrad Med Educ Res 2014;48:105-8.

19. Martins-Júnior PA, Franco FA, de Barcelos RV, Marques LS, Ramos-Jorge ML. Replantation of avulsed primary teeth: A systematic review. Int J Paediatr Dent 2014;24:77-83.

20. Malmgren B, Andreasen JO, Flores MT, Robertson A, DiAngelis AJ, Andersson L, et al. International Association of Dental Traumatology guidelines for the management of traumatic dental injuries: 3. Injuries in the primary dentition. Dent Traumatol 2012;28:174-82.

21. Hargreaves JA, Cleaton-Jones PE, Roberts GJ, Williams S, Matejka JM. Trauma to primary teeth of South African pre-school children. Endod Dent Traumatol 1999;15:73-6.

22. Kupietzky A, Holan G. Treatment of crown fractures with pulp exposure in primary incisors. Pediatr Dent 2003;25:241-7.

23. Assunção LR, Ferelle A, Iwakura ML, Nascimento LS, Cunha RF. Luxation injuries in primary teeth: A retrospective study in children assisted at an emergency service. Braz Oral Res 2011;25:150-6. 